\title{
The Paris and Liege Meetings of the Institution of Mechanical Engineers.
}

'THE summer meeting of the Institution of Mechanical Engineers was held on June I2-21 in Paris and Liége. In Paris the meetings were held in the Hall of the Société des Ingénieurs Civils de France. At the opening session M. Max Laubeuf, the president of the French society, and the engineer who more than any other has been responsible for the development of the submarine, received the president, Dr. H. S. Hele-Shaw, and members of the Institution of Mechanical Engineers, and addressed a few words of welcome. M. Laubeuf had expected to be away from France at the time of the meeting, and the formal address of welcome was therefore delivered by the vice-president, Prof. Leon Guillet.

The first paper was by Prof. Edouard Sauvage, on feed-water heaters for locomotives, in which various types were described, and the economies that might be expected from their use discussed. The second paper was an important contribution from Sir Vincent Raven on the electric locomotive. Broadly speaking, there are three types of locomotives required for the successful working of railways, namely: shunting, freight or goods, and passenger locomotives. For passenger traffic it is not so easy to standardise locomotives as for the other purposes, and considerable difficulties are met with in designing high-speed locomotives of great power. Particulars of a number of electric locomotives designed by the author and others were given, but the most interesting was an experimental locomotive that had been designed by Sir Vincent Raven, and built by the North Eastern Railway to haul a train of $45^{\circ}$ tons, of sufficient power to start from rest on a rising gradient of $\mathrm{x}$ in 78 , to reach a speed of $6_{5}$ miles an hour on the level, and to run with safety at 90 miles per hour. The paper is an important one, and will arouse considerable interest. The chief engineer of the Paris-Lyon Railway, who is considering the same problems, spoke enthusiastically of Sir Vincent Raven's work. The agreement of these two engineers to compare their experiences is a real example of that entente cordiale which such gatherings must of necessity do so much to encourage. Lord Montagu of Beaulieu, in a paper on mechanical vehicles and road surfaces, directed attention to the economic importance of good road surfaces.

The first paper read on the second morning at Paris was a very important contribution by Prof. A. Rateau on the subject of rapid high-altitude flying. The author pointed out that the aeroplane is the only vehicle in which the resistance to travel is independent of the speed, and is directly proportional to the weight for the same angle of incidence. For high speeds, the aeroplane must select a height at which the density of the air is most suitable, and, providing the power of the engine can be maintained, high speeds can most easily be obtained at high altitudes. The rarefaction of the atmosphere at high altitudes makes it impossible without some special device to maintain the power of the engine, and, furthermore, pilots and passengers cannot exist in the rarefied atmosphere without special provision of oxygen, or being in an air-tight chamber to which air can be supplied under pressure. Prof. Rateau has attempted to overcome the former difficulty by using exhaust gases from the engine to drive a turbine compressor which will supply air to the engine at ground-level pressure, and also, it is hoped, to the pilot and passengers in the air-tight chamber. Although in this country, in France, and in Germany a good deal of attention has been paid to supercharging of the engine in order to maintain power, Prof. Rateau's paper is the most serious contribution that has been published on the subject. In certain trials the turbocompressor was made to revolve at speeds up to 53,000 revolutions per minute, giving a peripheral speed of $670 \mathrm{~m}$ : per second at the tips of the compressor. In the gas turbine, speeds were attained which gave stresses due to centrifugal force equal to 123,000 times the weight of the material. Moreover, the turbine is worked at a temperature of from $650^{\circ}$ to $750^{\circ} \mathrm{C}$., and thus very unusual demands are made upon the material.

Prof. Rateau's paper was followed by one on aircompressors by Mr. W. Reavell, of Ipswich, and this again by a paper on the supersaturated condition as shown by nozzle flow, by Prof. A. L. Mellanby and Mr. W. Kerr. It has been suggested that an explanation of the discharge through a nozzle being greater than that required by theory can be found by the assumption that the rate of change of pressure in a nozzle is so great that supersaturation of the steam takes place. The assumption is apparently justified by Wilson's experiments, but it is difficult to see how the conditions for a Wilson effect could be obtained in a nozzle. Prof. Mellanby's experiments confirm those of other workers in showing that the flow is greater than could possibly obtain if the steam did not become partially supersaturated. In the apparatus used search tubes were placed in the nozzles to determine the drop of pressure along the nozzle, and from an examination of these and the discharge through the nozzles, the condition of the steam was obtained. The experiments show that the flow at and near the dry state is excessive when compared with the theoretical, but that the form of the flow curve over a small range of superheat beyond the initially dry condition is not in agreement with the assumption of complete supersaturation.

The last paper read at Paris was one by Prof. F. C. Lea on the effect of temperature on some of the properties of metals, in which it was shown that the effect of temperature on the elastic properties of metals may be more important than upon the ultimate breaking strengths. The significance of this paper was well illustrated by the difficulties referred to by Prof. Rateau in his paper on turbo-compressors.

An interesting and important public lecture was given by Prof. E. G. Coker, on Recent Photo-Elastic Researches on Engineering Problems. The lecture was illustrated by a number of large scale experiments, showing the stress produced in wheel teeth transmitting power and in material being cut in the lathe in planing machines and in milling machines. The experiments aroused much interest and enthusiasm, and the lecturer is to be very sincerely congratulated upon the success of a lecture necessitating the conveyance to France of so much delicate apparatus.

A distinguished gathering was held at the Hôtel

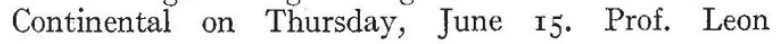


Guillet, responding to the toast of the French engineering society, replied eloquently, recounting the work that had been done concurrently by French engineers and men of science in the many developments that had taken place during the last century.

Following the very successful meetings in Paris, members of the Institution journeyed to Liége to participate with l'Association des Ingénieurs sortis de l'École de Liége in the celebration of the seventyfifth anniversary of the foundation of the Liége Society, which coincided also with the seventy-fifth anniversary of the foundation of the Institution of Mechanical Engineers. In connexion with this anniversary an international scientific congress and exhibition had been arranged by the Liége Society, and this was opened by the King of the Belgians on June I8. The members of the Institution of Mechanical Engineers received invitations to the opening ceremony. The King in his opening address referred in particular to the importance of the work of men of science and of engineers in developing the resources of the world. On the days following the opening of the exhibition a number of papers were read at various sections of the Congress, and visits were arranged to works in the neighbourhood of Liége. Representatives of the French engineering society journeyed to Liége with the members of the Institution of Mechanical Engineers, and the association of the three societies proved of the greatest interest. It is believed and hoped that the celebrations will do much to bring about that rapprochement between the three peoples which is so essential for the future welfare of Europe and the world.

\section{Absolute Measurements of Sound. ${ }^{1}$}

By Dr. Arthur Gordon Webster, Professor of Physics, Clark University, Worcester, Mass., U.S.A.

$\mathrm{T}^{\mathrm{T}}$ is now more than thirty years since it occurred to 1 me to devise an instrument that should be capable of measuring the intensity or loudness of any sound at any point in space, should be self-contained and portable, and should give its indications in absolute measure. By this is meant that the units should be such as do not depend on time, place, or the instrument, so that, though the instrument be destroyed and the observer dead, if his writings were preserved another instrument could be constructed from the specifications and the same sound reproduced a hundred or a thousand years later. The difficulty comes from the fact that the forces and amounts of energy involved in connexion even with very loud sounds are extremely small, as may be gathered from the statement that it would take approximately ten million cornets playing fortissimo to emit I horse-power of sound.

Before we can measure anything we must have a constant standard. In sound we must construct a standard which emits a sound of the simplest possible character, which we call a pure tone; it will be like that emitted under proper conditions by a tuning-fork, which is described by saying that the graph representing the change of pressure with the time shall be that simple curve known as the sinusoid or curve of sines. From this connexion we say that the pressure is a harmonic function of the time. Unfortunately, the pressure change is so small that at no point in a room, even when a person is speaking in a loud tone, does the pressure vary from the atmospheric pressure by more than a few millionths of an atmosphere. Thus we require a manometer millions of times as sensitive as an ordinary barometer, and, in addition, since the rhythmic changes occur, not once in an hour or day, but hundreds of times per second, if we wish the gauge to follow the rapid changes accurately, we have many mechanical difficulties.

The problem of a standard of emission has been solved by a number of persons, including Prof. Ernst Mach and Prof. Ludwig Boltzmann, and Dr. A. Zernov, of Petrograd, a pupil of the celebrated Peter Lebedeff. The problem of an absolute instrument for the reception and measurement of a pure tone has been also success-

\footnotetext{
${ }^{3}$ From a Friday evening discourse delivered at the Royal Institution on June 10, I921.
}

fully dealt with by a number of investigators, among whom may be mentioned Prof. Max Wien, of wireless fame, the late Lord Rayleigh, and Lebedeff. But there remains a third step in the process, which is as important as the first and the second. Given the invention of the proper standard source of sound, which I have named the "phone," because it is vox et praeterea nihil, and of a proper measuring instrument, which should evidently be called a phonometer, there still remains the question of the distribution of the sound in space between the phone and the phonometer. Any measurements made in an enclosed space will be influenced by reflections from the walls, and, even if we had a room of perfectly simple geometrical form, say cubical, and were able to make the instruments of emission and reception work automatically without the disturbing presence of an observer, it would still be impossible to specify the reflecting power of the walls without a great amount of experimentation and complicated theory. Nevertheless, this is exactly what was done by the late Prof. Wallace C. Sabine, of Harvard University, who employed the human ear as the receiving instrument. Those who have made experiments upon the sensitiveness of the human ear for a standard sound will immediately doubt the possibility of making precise measurements by the same ear at different times, and particularly of comparing measurements made by one ear with those made by another. Nevertheless, Sabine attained wonderful success and was able to impart his method to pupils who carried on his work successfully, so that he was able to create the science of architectural acoustics and to introduce a new profession. Still, the skill that required three or four months to attain by Sabine's method may be replaced by a few minutes' work with the phonometer.

In order to avoid the influence of disturbing objects, the observer should take the phonometer to an infinite distance, which is manifestly impossible. The method employed was to get rid of all objects except a reflecting plane covered with a surface the coefficient of reflection of which could be measured. For this purpose the teeing ground of a suitable golf course was used. With the present instrument it can be determined in a few minutes, if there is no wind. 